\title{
Anthropometrical Parameters of the Orthognathic Bite in People of Uzbek Nationality
}

\author{
Saidmurodkhon S. Murtazaev, PhD*; Irina E. Pak; Saydialo Murtazaev, PhD, ScD \\ Tashkent State Dental Institute, Tashkent, Uzbekistan
}

\begin{abstract}
The aim of our work was to study anthropometric characteristics of jaws for Uzbek people with an orthognathic bite.

Material and Methods: The study included 42 ethnic Uzbeks (20 women and 22 men) aged from 17 to 25 years with a developed orthognatic bite; the control group consisted of the 25 age- and sex-matched Caucasians and Southern Altaians (mongoloids). The object of the research was 86 dental casts of upper and lower jaws of young Uzbek volunteers of both genders. Measurements were carried out on the plaster casts in sagittal and transversal directions using anthropometric measurement methods.

Results: The total width of 4 upper incisors in Uzbek females and males was less than that of South Altaians; the width of upper and lower dentitions at the level of the first premolars, second premolars and first molars was significantly more than that of Caucasians.

Conclusion: The ascertained features of the tooth size, the dentition size and form should be taken into account when the orthodontic arches are being chosen for treatment of dental and maxillary anomalies.
\end{abstract}

Keywords: orthognathic bite; anthropometric reference points; Pont's index; plaster casts of jaws.

\section{Introduction}

Diagnostic dental casts represent the clinical condition of the oral cavity, and dimensions made on them facilitate determination of particularities of an existing anomaly or deformation. These casts are necessary for making a diagnosis and plan of treatment and also for determining the most appropriate type of orthodontic appliance [1]. When losing teeth, the re-creation of bite becomes problematic because parameters of the rows of teeth in correlation with proportions of the head, face and jaws in different ethnic groups are not determined in contemporary anthropomorphology and dentistry. Therefore, bite evaluation according to the nature of how tooth rows close does not meet modern demands and the potential of the science [2-10].

Determination of the dimensions of tooth rows of the orthognathic bite in the proportionally hierarchical network of face and head, performed on a naturally volumetrical arrangement of structures in a live person, is not only for ethnic

*Corresponding author: Saidmurodkhon S. Murtazaev, PhD. Head of the Pediatric Dentistry Department. Tashkent State Dental Institute. Tashkent, Uzbekistan.E-mail: Saidmurodtma@mail.ru anthropology and clinic anatomy but also for cosmetology, oral surgery, orthodontics, and prosthodontics, especially when reconstruction of teeth, tooth rows and tainted bite take place, as well as in forensic medicine for personality identification. Determination of parameters of the orthognathic bite in people of Uzbek nationality, and identification of a correlation with a common shape of the head and face, tooth rows and teeth, becomes the actual problem [11-14].

Objective of our work was to study anthropometric characteristics of jaws for Uzbek people with an orthognathic bite.

\section{Material and Methods}

The study included 42 ethnic Uzbeks (20 women and 22 men) aged from 17 to 25 years with a developed orthognatic bite. Written informed consent was obtained from each patient. The control group consisted of the 25 age- and sex-matched Caucasians and Southern Altaians (mongoloids) according to O.D. Baydik [7]. The study was approved by the Tashkent State Dental Institute Ethics Committee.

The orthognathic bite was determined by the following criteria:

1. Upper lateral teeth cover the lower ones on the depth 
of the longitudinal fissure and in the frontal part, upper incisors cover lower incisors by $1 / 3$ of the length of the crown;

2. Each tooth has two antagonists except for the lower central incisors and upper third molars;

3. The centerline between the central incisors of the upper and lower jaws coincides;

4. The length of the crowns decreases from central incisors to molars, except for canines;

5. A multiple fissure-papulose contact;

6. Angle's class I occlusion (or neutroclusion) on the right and left.

The object of the research was 86 dental casts of upper and lower jaws of young Uzbek volunteers of both genders. Measurements were carried out on the plaster casts in sagittal and transversal directions using anthropometric measurement methods.

All subjects tested were born and lived in the territory of the Republic of Uzbekistan; all of them grew up and were formed in the same geo climatic conditions, namely in an acutely continental region. We determined ethnic heritage by surveying and identifying representatives' genealogy for four generations: 1).The proband; 2).The proband's mother and father; 3).The proband's grandmother and grandfather from the mother's and father's line; 4).The proband's great grandmother and great grandfather from the mother's and father's line. Research included the probands whose ancestors belonged to the same ethnic group.

Observable groups included people selected according to the following criteria: normally functioning tooth-jaw-facial system and masticatory efficiency and the decayed, missing, and filled teeth (DMFT) index. Absence of any tooth was not acceptable. All examined did not have any morphological and functional deviations from accepted standards and were characterized by absence of clinical pathologies. None of them had previously received orthodontic treatment. As for social status, all of them were students of different institutes and universities of Tashkent city.

\section{Position of teeth and the dimension of tooth rows}

Tooth position was determined in three mutually perpendicular directions. In the transverse direction, the Pont's method was used to determine the individual norm of the width of tooth rows [15]. A. Pont established a correlation between the sum of the width of four upper incisor crowns and the width of tooth rows in the area of premolars and molars. To determine this correlation, we measured the width of crowns of the upper incisors and the distance between Pont's checkpoints on the chewing surface of the first premolars and molars. A.Pont discovered premolar and molar indices. He concluded that in the ideal dental arch (in the French population) the ratio of combined incisor width to transverse arch width was .80 in the premolar area (Premolar index=80) and .64 in the molar area (Molar index $=64)$. In the orthognathic bite, the width of upper and lower tooth rows is the same because checkpoints on the upper teeth in a central occlusion match checkpoints on the lower teeth.

H. Linder and G. Harth [16 ] made corrections in index numbers by using Pont's method. According to these authors, the premolar index is equal to 85 , and the molar to 65 . In practice, doctors can use these numbers for to measure tooth rows in the period of mixed and permanent dentition.

Dimensions in the sagittal direction were conducted by G. Korkhaus's method [17]. G. Korkhaus complemented Pont's method by assuming that the length of the frontal part of upper tooth row could be determined in relation to the sum of the width of crowns of upper incisors. To determine existing length, we measured the distance from the midpoint between the central incisors from the vestibular surface of their crown along the midline of the jaw to its intersection with the line connecting Pont's point on the first premolars. The length of the frontal part of the lower tooth row was calculated by subtracting two millimeters from the quantity of the frontal part of the upper tooth row (the thickness of the incisal edge of upper central incisors).

Received results were processed by the method of variation statistics on computer IBM PC Pentium-IV with use of Microsoft Excel programs for Windows 2003. All values are presented as mean \pm SEM. For data with normal distribution, inter-group comparisons were performed using Student's t-test. A value of $\mathrm{P}<0.05$ was considered statistically significant.

\section{Results and Discussion}

We were the first to carry out biometric measurements of teeth on jaw casts of Uzbek people for identification of racial and ethnic differences. The total width of 4 upper incisors in Uzbek females and males was less than that of South Altaians (Table 1).

According to the data of O.D. Buydik [7], Mongoloids have an inclination to macrodontia. Macrodontia is considered as pathogenetic factor of dentition anomalies in orthodontics. M. Abu-Hussein and A. Sarafianou [10] consider macrodontia as an ethnic variant of normality. It is interesting that apart from a significantly low sum of the 4 upper incisors' width in Uzbek males and females, the width of upper and lower dentitions at the level of the first premolars, second premolars and first molars was significantly more than that of Caucasians. The length of frontal segments of the upper and lower dental arches was also more than that of Caucasians; additionally, the premolar and molar Pont's indexes were less than those of South Altaians and Caucasians (Table 1).

Studying the jaws, dentitions and teeth and determining the connection among them allows us to detect more reliable features of bite, which can help to develop jaw analogue casts and working casts for restoration of dentitions, taking into account the racial and ethnic features of the patient.

On the basis of our analysis we arrived at the conclusion that indexes for Caucasian dentitions developed by Pont and Linder-Hart may be causes of mistakes in diagnostics of dentition anomalies of people of other races and ethnic groups. The ascertained features of the tooth size, the dentition size and form should be taken into account when the orthodontic arches are being chosen for treatment of dental and maxillary anomalies. 
Table 1.

Anthropometric parameters of the upper and lower dentitions in Uzbeks, Caucasians and Southern Altaians

\begin{tabular}{|c|c|c|c|c|}
\hline Tooth row & Parameters & $\begin{array}{l}\text { Southern Altaians } \\
\qquad \mathrm{n}=79\end{array}$ & $\begin{array}{c}\text { Caucasians } \\
\mathrm{n}=40\end{array}$ & $\begin{array}{c}\text { Uzbeks } \\
n=42\end{array}$ \\
\hline & Total width of four upper incisors, $\mathrm{mm}$ & $31.33 \pm 0.25$ & $29.75 \pm 0.36$ & $29.88 \pm 0,29 *$ \\
\hline & Width of tooth row at the level $6 \mid 6, \mathrm{~mm}$ & $49.59 \pm 0.38$ & $46.46 \pm 0.55$ & $50.49 \pm 0.74^{\wedge}$ \\
\hline \multirow{4}{*}{$\begin{array}{l}\mathrm{p} \\
\mathrm{p} \\
\mathrm{e} \\
\mathrm{r}\end{array}$} & Width of tooth row at the level $4 \mid 4, \mathrm{~mm}$ & $37.47 \pm 0.29$ & $35.30 \pm 0.45$ & $38.63 \pm 0.62$ \\
\hline & Pont's molar index, \% & $63.24 \pm 0.74$ & $64.05 \pm 0.52$ & $60.33 \pm 1.11^{* \wedge}$ \\
\hline & Pont's premolar index, $\%$ & $83.69 \pm 0.93$ & $84.90 \pm 0.62$ & $77.05 \pm 1.06^{* \wedge}$ \\
\hline & Length of the frontal part of tooth row, $\mathrm{mm}$ & $16.72 \pm 0.23$ & $12.39 \pm 0.17$ & $16.1 \pm 0.22^{\wedge}$ \\
\hline \multirow[b]{2}{*}{$\mathrm{L}$} & Total width of four lower incisors, $\mathrm{mm}$ & $22.25 \pm 0.55$ & $22.41 \pm 0.24$ & $21.7 \pm 0.18$ \\
\hline & Width of tooth row at the level $6 \mid 6, \mathrm{~mm}$ & $48.31 \pm 0.59$ & $46.28 \pm 0.67$ & $51.3 \pm 0.75^{\wedge}$ \\
\hline \multirow{2}{*}{$\begin{array}{c}\mathrm{O} \\
\mathrm{W}\end{array}$} & Width of tooth row at the level $4 \mid 4, \mathrm{~mm}$ & $36.30 \pm 0.34$ & $34.06 \pm 0.48$ & $37.4 \pm 0.66^{\wedge}$ \\
\hline & Pont's molar index, \% & $47.88 \pm 0.92$ & $48.45 \pm .077$ & $42.75 \pm 0.61^{* \wedge}$ \\
\hline \multirow{2}{*}{$\mathrm{r}$} & Pont's premolar index, $\%$ & $63.26 \pm 1.22$ & $65.89 \pm 1.14$ & $58.7 \pm 0.71^{* \wedge}$ \\
\hline & Length of the frontal part of tooth row, $\mathrm{mm}$ & $16.59 \pm 0.34$ & $11.81 \pm 0.24$ & $14.1 \pm 0.22^{* \wedge}$ \\
\hline
\end{tabular}

$P<0.05$ vs Southern Altaians; $\wedge_{-}-P<0.05$ vs Caucasians .

\section{Competing interests}

The authors declare that they have no competing interests.

\section{References}

1. AlHarbi S, Alkofide EA, AlMadi A. Mathematical analysis of dental arch curvature in normal occlusion. J Angle Orthod 2006; 78 (2):281-7.

2. Bayome M, Sameshima GT, Nojima K, Baek SH, Kook YA. Comparison of arch forms between Egyptian and North American white populations. Am J Orthod Dentofacial Orthop 2011; 139(3):e245-52.

3. Bharati S, Som S, Bharati P, Vasulu TS. Climate and head form in India. Am J Hum Biol 2001; 13(5):626-34.

4. Gafni Y, Tzur-Gadassi L, Nojima K, McLaughlin RP, Abed Y, Redlich M. Comparison of arch forms between Israeli and North American white populations. Am J Orthod Dentofacial Orthop 2011; 139(3):339-44.

5. Kook, YA, Nojima K, Moon HB, McLaughlin RP, Sinclair PM. Comparison of arch forms between Korean and North American white populations. Am J Orthod Dentofacial Orthop 2004; 126(6):680-6.

6. Burris BG, Harris EF. Maxillary arch size and shape in American blacks and whites. Angle Orthod 2000; 70(4):297-302.

7. Baydik O.D. Morphological evaluation criteria orthognathic bite representatives of different ethnic groups. PhD Thesis. Barnaul; 2005.[in Russian]

8. Hendrikson J, Persson M, Thilander B. Long-term stability of dental arch in normal occlusion from 13 to 31 years of age. Eur J Orthod 2001; 23(1):51-61.

9. Kook YA, Bayome M, Park SB, Cha BK, Lee YW, Baek $\mathrm{SH}$. Overjet at the anterior and posterior segments: threedimensional analysis of arch coordination. Angle Orthod 2009; 79(3):495-501.

10. Abu-Hussein M, Sarafianou A. Mathematical analysis of dental arch of children in normal occlusion. Intern $\mathrm{J}$ Med Dentistry 2012; 2(1):33-40.

11. Nojima K, McLaughlin RP, Isshiki Y, Sinclair PM. A comparative study of Caucasian and Japanese mandibular clinical arch forms. Angle Orthod 2001; 71(3):195-200.

12. Olmez S, Dogan S. Comparison of the arch forms and dimensions in various malocclusions of the Turkish population. Open J Stomatol 2011; 1:158-64

13. Yun YK, Kook YA, Kim SH, Mo SS, Cha KS, Kim JG, et al. Mandibular clinical arch forms in Koreans with normal occlusions. Kor J Orthod 2004; 34:481-7.

14. Kim BI, Bayome M, Kim Y, Baek SH, Han SH, Kim $\mathrm{SH}$, et al. Comparison of overjet among 3 arch types in normal occlusion. Am J Orthod Dentofacial Orthop 2011;139(3):e253-60.

15. Pont A. Der zahnindex in der Orthodontie. Z Zahnartl Orthop 1909; 3:306-12.

16. Linder H. Biometrische Untersuchungen des Normalgebisses in verschiedenen Lebensaltern. Fortschr Orthodont 1931; 1(22):211-4.

17. Korkhaus G. G.GebiB, ed. Handbuch der Zahnheilkunde Kiefer- und Gesichtsorthopadie. Bd. IV. Bergmann, Munchen; 1939. 